\title{
El hormigón armado en Cataluña (1898-1929): cuatro empresas y su relación con la arquitectura
}

\section{Reinforced concrete in Catalonia (1898-1929): four companies and their relationship with architecture}

$\underline{\text { R. Graus }}^{(*)}$, H. Martín Nieva ${ }^{(* *)}$, J. Rosell ${ }^{(*)}$

\section{RESUMEN}

Entre 1898 y 1929 se desarrollaron en Cataluña variadas iniciativas empresariales que introdujeron el hormigón armado en la arquitectura. En el artículo se estudian las empresas Anónima Claudio Duran - Construcciones Monier, Marial Hermanos - Sociedad Colectiva, Construcciones y Pavimentos, S. A., y Material y Obras, S. A. Se propone una aproximación al entramado productivo que estudie las empresas, sus técnicos y sus obras en toda su complejidad con la intención de valorar cómo el hormigón armado transformó el sector de la construcción, con nuevas empresas de otra escala productiva. Sin embargo, el ciclo económico depresivo 1929-1952 lastró estas iniciativas y alargó artificialmente los restos de la tradicional «construcción catalana».

Palabras clave: historia de la arquitectura; historia de la construcción; hormigón armado; Monier; Hennebique; construcción catalana.

\section{ABSTRACT}

Between 1898 and 1929 various business initiatives that introduced reinforced concrete in its architecture developed in Catalonia. This article studies the following four companies: Anónima Claudio Duran - Construcciones Monier, Marial Hermanos - Sociedad Colectiva, Construcciones y Pavimentos, S. A. and Material y Obras, S. A. Only thorough knowledge of the production complexities that studies these companies, their technicians and works in all its complexity will allow us to assess how reinforced concrete transformed the construction sector, with new companies of a different productive scale. However, the depressed economic cycle of 1929-1952 weighed down any initiative and artificially lengthened what was left of traditional "Catalan construction".

Keywords: history of architecture; history of construction; reinforced concrete; Monier; Hennebique; Catalan construction.

(*) GRHACCI, Universitat Politècnica de Catalunya, Barcelona (España).

(**) La Salle, Universitat Ramon Llull, Barcelona (España).

Persona de contacto/Corresponding author: ramon.graus@upc.edu (R. Graus)

ORCID: http://orcid.org/oooo-0oo2-5010-1593 (R. Graus); http://orcid.org/oooo-ooo1-6310-8391 (H. Martín Nieva); http://orcid.org/oooo-0002-9152-8876 (J. Rosell)

Cómo citar este artículo/Citation: Graus, R., Martín Nieva, H., Rosell, J. (2016). El hormigón armado en Cataluña (1898-1929): cuatro empresas y su relación con la arquitectura. Informes de la Construcción, 69(546): e200, doi: http://dx.doi.org/10.3989/ic.16.004.

Copyright: (c) 2017 CSIC. Licencia / License: Salvo indicación contraria, todos los contenidos de la edición electrónica de Informes de la Construcción se distribuyen bajo una licencia de uso y distribución Creative Commons Attribution License (CC BY) Spain 3.o. 
El hormigón armado había llegado a España a finales del siglo XIX por medio de la patente francesa Monier. Francesc Macià i Llussà, ingeniero militar y político, introducía en España a través de Cataluña, con la mirada puesta en la modernización de la agricultura, el nuevo sistema como una técnica que permitía fabricar depósitos para contener líquidos. Poco tiempo después entraría en España la patente francesa Hennebique, mediante diversos concesionarios, el más capaz de los cuales fue el ingeniero de caminos José Eugenio Ribera Dutaste.

Éstos serían los primeros pasos de varios más que in crescendo experimentaría la técnica del hormigón armado en el primer tercio del siglo XX, en un camino paralelo al crecimiento del país que, con altibajos, culminaría con el pleno dominio de la técnica. La crisis económica de los años treinta, la Guerra Civil y la larga posguerra truncaron la continuidad de muchas iniciativas. La técnica, parcialmente adulterada por la penuria, necesitó unos años para ser recuperada. Pero también se perdió el hilo narrativo de la aventura que había supuesto aquella innovación. Reconstruir aquella aventura ha precisado un proceso de investigación histórica que ha tenido varias etapas: un primer momento marcado por esbozos generalistas a través de testimonios directos o recuerdos cercanos (1) (2) (3), un segundo momento marcado por aproximaciones biográficas de algunos pioneros (4) (5), por el interés por las patentes como sistema de transferencia tecnológica (6) (7) (8) y por el estudio de edificios concretos (9), y un tercer momento en el que ha sido posible esbozar unas primeras historias panorámicas de los inicios del hormigón armado (10) (11). Todavía hoy se está lejos de poder recomponer la complejidad de los hechos. Las páginas que siguen incluyen una aproximación al problema centrándose en el trabajo en Cataluña de cuatro empresas y el de sus técnicos.

\section{DURAN}

Pocos años después de la constitución por parte de Francesc Macià de Lecanda, Macià y Cía., que explotaba aproximadamente desde el año 1893 para toda España la patente Monier de hormigón armado, en el año 1898, la familia Macià y otros socios optaron por retirarse a un discreto papel de comanditarios y dejaron el control y la cabecera de la sociedad al arquitecto Claudi Duran i Ventosa (1864-1925) que aportaría el $50 \%$ del nuevo capital cifrado en 50.000 pesetas. Efectivamente, en 1898, la compañía pasó a denominarse Claudio Duran, Sociedad en Comandita, con un contrato de permanencia de 8 años. En aquel momento se adquirieron unos terrenos en Can Tunis, al pie del cementerio barcelonés de Montjuïc, donde se instalaron los talleres (12).

Todo parece indicar que Duran deseaba transformar aquella pionera compañía catalana de hormigón armado, destinada a la construcción de depósitos y otros elementos útiles para la modernización de la agricultura, en una empresa de construcción general que utilizase la totalidad de técnicas del hormigón armado que la misma patente Monier permitía desarrollar.
Hasta ese momento Duran era un arquitecto que buscaba su hueco en la profesión: titulado en 1888, había colaborado con Elies Rogent en las obras de la Exposición de 1888, trabajaba para la diócesis de Solsona desde 1892 y para el municipio de Horta desde 1894, y, desde 1896, había accedido a la Escuela de Arquitectura de Barcelona como profesor auxiliar de los catedráticos Antoni Rovira Rabassa y Joan Torras Guardiola. Por tanto, era un joven arquitecto preparado también para el cálculo y la construcción. Duran, como había hecho su maestro Torras con el hierro laminado (13), tenía esperanzas fundadas en poder atender las necesidades de sus colegas arquitectos, desconocedores de una técnica emergente.

Siguiendo los pasos de las modernas empresas de hormigón armado, Duran emprendió una potente campaña publicitaria. Así, anunciaba sus servicios en revistas como El Cemento Armado, Revista Tecnológico-Industrial, Arquitectura y Construcción o Anuario de la Asociación de Arquitectos de Cataluña. Del Anuario de 1905 procede una doble página de publicidad (Figura 1) que contiene una viñeta protagonizada por seis de los siete enanitos del cuento de los hermanos Grimm convertidos en alegres e infatigables trabajadores de esa mina de oro que podía ser el hormigón armado. Este anuncio iba acompañado de una fotografía que mostraba los talleres de la empresa como trasfondo de un palomar de cemento armado, un prototipo de planta octogonal, con unos macizos en voladizo sobre una estructura esbelta y ligera, con una escalera helicoidal en el centro; un edificio levantado expresamente para mostrar las posibilidades de la nueva técnica: «Ligereza - Esbeltez - Impermeabilidad - Solidez Economía - Resistencia a las heladas - Incombustibilidad Rapidez de construcción». Todo un programa de futuro para la construcción y la arquitectura.

La empresa continuó vendiendo depósitos, pero lentamente llegarían obras de mayor envergadura: en 1901, con el proyecto del arquitecto Francesc Lamolla se construirán las grandes balsas depuradoras de Lleida; en 1902, también a través de otro arquitecto, Andreu Audet, construirá los depósitos de agua del Hotel Colón de Barcelona; más tarde, en 1906, levantará el Sindicato Agrícola de Alella, donde sólo fabricará algunos depósitos de hormigón armado mientras el edificio será construido de forma tradicional. También intentará la expansión del negocio lejos de Barcelona, así reparará el depósito de Mieres, bajo la dirección de Eugenio Ribera (14), y construirá los depósitos de melazas de las azucareras de Arganda del Rey (también subcontratado por Ribera), de Alagón, e Ibérica de Zaragoza, y construirá el monumento en conmemoración del dogma de la Inmaculada, en forma de árbol visitable, en la Peña de Orduña.

Con todo, las previsiones iniciales no se concretaban y la empresa no era viable. La extinción, en 1906, de los pactos establecidos en el contrato de constitución permitía replantear la empresa, aunque los nuevos cambios no llegaron hasta fines de 1908, cuando la sociedad fue liquidada (15), desaparecieron los antiguos comanditarios y se creó Anónima Claudio Duran-Construcciones Monier (16). La sociedad anónima ofrecía una mayor seguridad jurídica ${ }^{1}$ y permitía una mayor y más fácil movilización de capital. Efectivamente, el nuevo

\footnotetext{
${ }^{1}$ La memoria del accidente del tercer depósito del Canal de Isabel II de Madrid (abril de 1905), que dirigía José Eugenio Ribera, estaba aún en el recuerdo de los profesionales.
} 


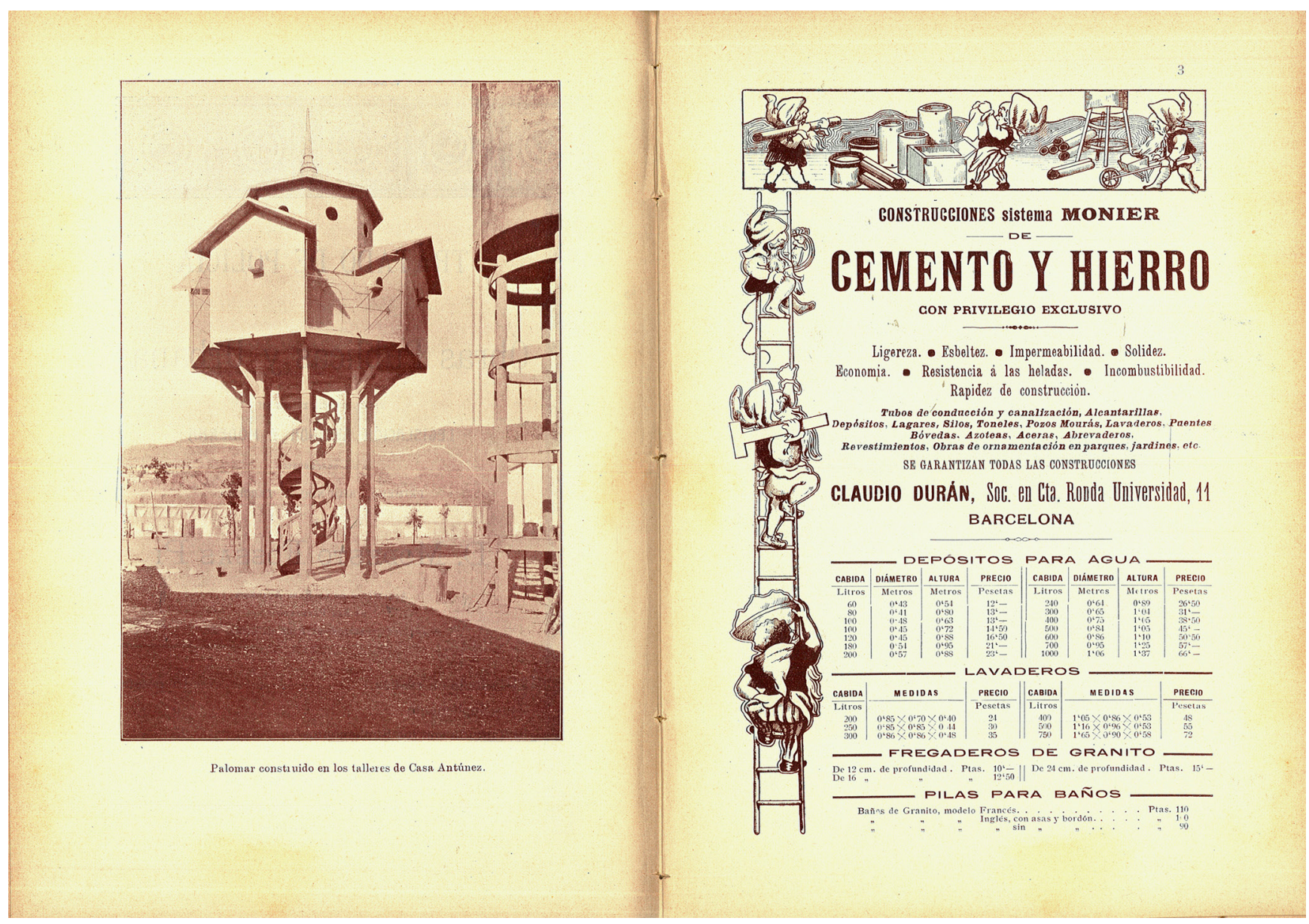

Figura 1. Claudi Duran: doble página de publicidad en el Anuario de la Asociación de Arquitectos de Cataluña, 1905.

capital sería de 500.000 pesetas $^{2}$. Uno de los hermanos de Claudi, el abogado Raimon Duran i Ventosa sería el presidente del consejo de administración y, otro hermano, el ingeniero industrial Josep Duran i Ventosa, el consejero delegado, mientras Claudi Duran se reservaba la dirección técnica. Es evidente que las relaciones sociales y la influencia política eran otra condición necesaria para promover la empresa ${ }^{3}$.

Así, pues, la nueva flexibilidad económica de la empresa debía permitir más oportunidades, tal como se intentó en 1909 cuando se pusieron en circulación las acciones que quedaban en cartera y, a la vez, se realizaba una emisión de obligaciones (17). Durante los años 1909 y 1910 la sociedad construyó una serie de pequeños puentes y pasarelas en varios lugares de Cataluña: en la Ribera Salada, en la Granada del Penedès y, especialmente, un puente en Montcada sobre el río Besòs de 10 tramos rectos y una pasarela de 13 tramos sobre el cauce del río Anoia que unía Sant Sadurní con la barriada de Monistrol, en este caso con pilotes hincados de hormigón armado.

Entre otras obras, Duran fue pionero en la construcción de la primera generación de bodegas cooperativas del campo catalán: Alió en 1911 y Pla de Santa Maria en 1913. Debe tenerse en cuenta que durante aquellos años se empezaba a ganar la batalla para convencer a los vinicultores de las ventajas de encubar en depósitos de hormigón armado (18). Sin embargo, se trataba de edificios de construcción tradicional donde el hormigón armado sólo conformaba las estructuras productivas: silos, cubas, lagares, balsas o depósitos. Lentamente, el nuevo material será utilizado también para construir en el interior conjuntos hormigonados in situ: pilares, muros y forjados, que mejoraban el aprovechamiento del espacio. Éste fue el caso de los almacenes de Manuel Mariné en el Poblenou barcelonés (Figura 2), un edificio, proyectado y construido por la empresa en 1917, donde se disponían unos silos enterrados de gran envergadura utilizados para almacenar cereales. Con todo, la envolvente continuaba siendo de ladrillo en las paredes y madera o hierro en las armaduras de cubierta. Una envolvente tradicional que no dejaba ver la modernidad técnica de su interior.

Hacia 1914 los negocios seguían sin despegar ya que el arquitecto solicitó el reingreso al Ayuntamiento de Barcelona y, a finales de año, se anunciaba en la prensa como «Claudio Duran y Ventosa, arquitecto-constructor. Proyectos y presupuestos de toda clase de obras. Especialidad en las de

\footnotetext{
${ }^{2}$ Las acciones se distribuyeron de la manera siguiente: Claudi Duran se quedaría con casi 500 (un 49\%), otro centenar aproximadamente quedaría en manos de familiares directos (sus hermanos Anna, Josep y Raimon), que habían prestado dinero a la primera empresa, mientras otras 400 quedarían destinadas a reserva de cartera.

3 Cabe recordar que Claudi Duran era uno de los cinco hijos del eminente jurista y político Manuel Duran i Bas y que su hermano Lluís Duran i Ventosa fue diputado provincial, concejal del Ayuntamiento de Barcelona y vicepresidente de la Mancomunitat de Catalunya.
} 

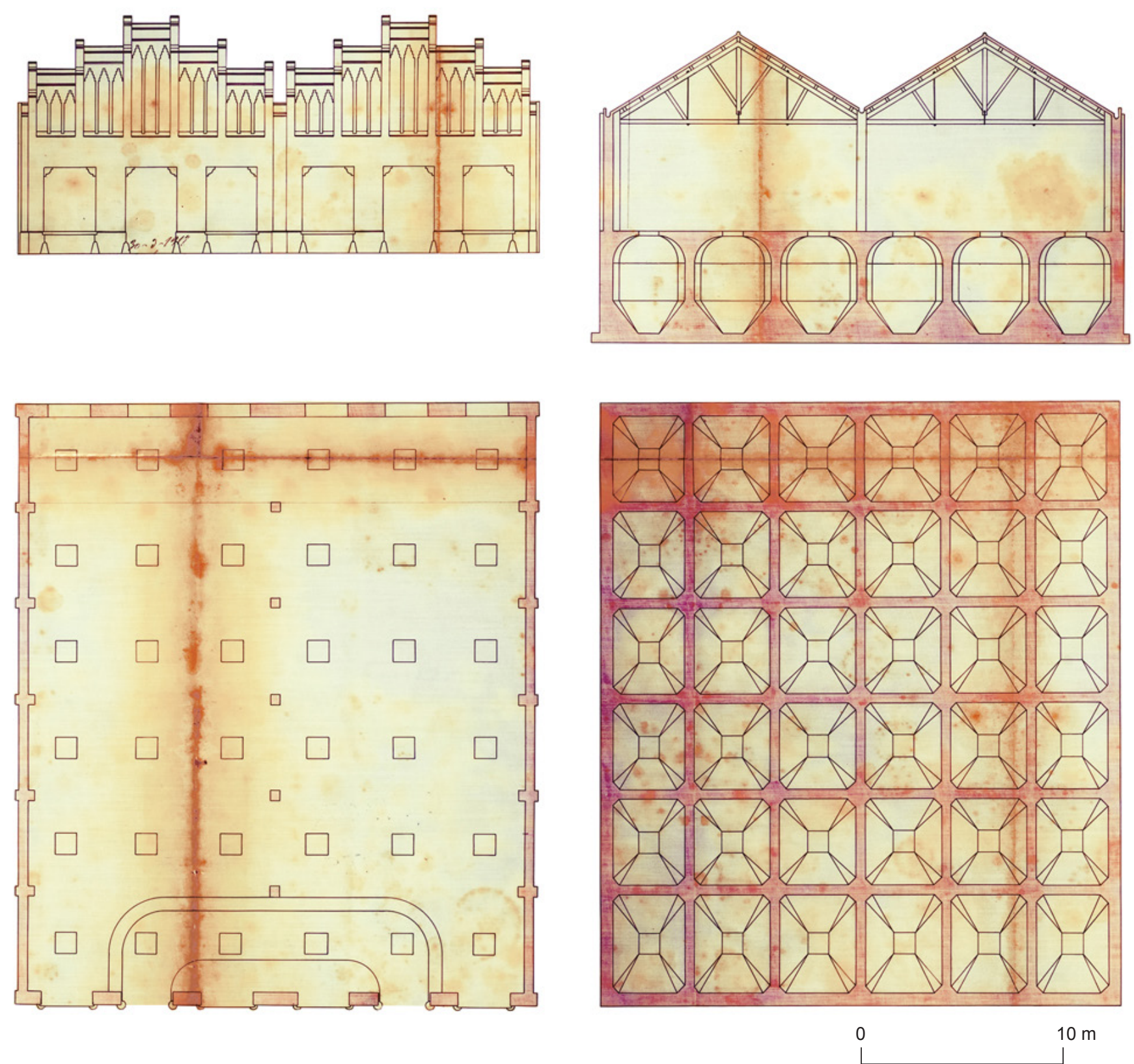

Figura 2. Claudi Duran: almacén y silos de cereales para Manuel Mariné (1917), Barcelona [Fuente: Arxiu Municipal Contemporani de Barcelona, Q127, exp. Eix-17074].

cemento y hormigón armado» (19), sin hacer ninguna referencia a la sociedad anónima y enfatizando el carácter personal de la oferta; el último anuncio publicado en el Anuario corresponde al año 1915, aunque la sociedad no fue efectivamente disuelta hasta 1918 (20).

Otras empresas desarrollarían con más fortuna las técnicas del hormigón armado. Al cabo de unos años, en 1925, Claudi Duran moriría en Barcelona. Entonces, su compañero Enric Catà escribiría: «Duran fue el primero que aplicó entre nosotros el sistema constructivo llamado "cemento armado"4 [...]. Cuando el cemento armado sólo servía para fabricar depósitos de agua, Duran tuvo la visión de las variadas aplicaciones que podía tener, y se estableció como Arquitecto-Constructor de obras de cemento armado [...]» (21).

Partiendo del campo puramente técnico, pero desbordándolo sin lugar a dudas, la aventura de Claudi Duran nos muestra de qué manera, al hilo de un ambiente de modernización, se introdujeron en Cataluña las nuevas técnicas de hormigón armado en un proceso de innovación que pasaba de las patentes a la generalización del sistema. Pero también, como se ha explicado, era un proceso que implicaba necesariamente una modernización de las empresas en un entramado de relaciones económicas, políticas y sociales propicias.

\footnotetext{
${ }^{4}$ En Cataluña se mantuvo durante la primera parte del siglo XX la expresión «ciment armat» ya que se trataba de una traducción literal del francés «ciment armé», el nombre que escogió Joseph Monier para bautizar su invención.
} 


\section{MARIAL}

El estallido, en 1914, de la Primera Guerra Mundial produjo una serie de distorsiones en la producción industrial de los países europeos que afectó también a los que no participaron directamente en la guerra. Cataluña se benefició de aquella situación ya que, desde la no intervención española, pudo trabajar para la economía de guerra. En este contexto la escasez de hierro, producida por las necesidades bélicas, se dejaba notar con fuerza y resultó ser uno de los factores que ayudaron, de distintas maneras y con distintas soluciones, a abrir paso al hormigón armado.

Ya hacía tiempo que el hierro formaba parte de la «construcción catalana», es decir, de aquella versátil manera de construir casas de alquiler, basada en la pared de carga de ladrillo y en la habilidad del albañil, ampliamente utilizada desde finales del siglo XVIII. Precisamente, a finales del siglo XIX las viguetas de hierro doble Thabían sustituido totalmente las antiguas de madera. La vigueta continuaba siendo un elemento fundamental de construcción que llegaba a la obra acabado, autoportante, se colocaba con gran facilidad apoyada sobre las paredes maestras y sostenía las bovedillas de ladrillo con las que conformaban los forjados y la azotea del edificio. El encarecimiento desproporcionado del hierro y del acero afectaría, pues, de manera notable a los costes de la construcción de la vivienda.

Una de las empresas con más solera del sector de la construcción de Barcelona era la familia Marial. Juli Marial Tey (1854-1929), maestro de obras titulado en 1872, era un popular constructor que había participado en las míticas obras de la Exposición de 1888 y en muchas otras obras importantes, siempre compatibilizando la dirección de la empresa con la política, como concejal del Ayuntamiento de Barcelona y como diputado a Cortes por La Bisbal. Marial dirigía la empresa apoyado en sus dos hijos, Juli Marial i Mundet y Melcior Marial i Mundet. El segundo había sido enviado a Bélgica a estudiar ingeniería y a su vuelta se convirtió en su principal puntal técnico.

Uno de los caminos de modernización de aquellos años de dificultades de suministro era sustituir las viguetas de acero de los forjados por otras parecidas, de hormigón armado, que presentasen unas prestaciones parecidas. Éste era un campo ya explorado en España (22) y en el extranjero, pero que se adaptaba a la ya larga tradición catalana de prefabricación de las empresas de piedra artificial. Con estos antecedentes, los Marial iniciaron los estudios para una patente que mejorase las prestaciones de las viguetas de hormigón armado, que fundamentalmente apuntaban a una reducción del peso que las hiciera más manejables y a un rediseño de su forma para recibir la bovedilla de ladrillo en los forjados de la construcción catalana.

En la primera patente presentada en 1916 partieron de una vigueta de doble ala con alma aligerada por alvéolos situados entre los estribos de la armadura (23). Al cabo de unos meses presentaron unas modificaciones que consistían en añadir dos redondos de montaje en la cabeza comprimida para mejorar la resistencia de la viga en la fase de transporte e izado en la obra y, por otro lado, modificaron el ala inferior cambiando su sección, redondeándola por debajo por si debía dejarse vista y suavizando a 45 grados el apoyo de las bovedillas (Figura 3) (24). Todavía se producirá una nueva modificación consistente en modificar los estribos para mejorar el proceso de fabricación (25). Paralelamente se registraba el nombre de Semper-ita como la marca publicitaria del producto (26).

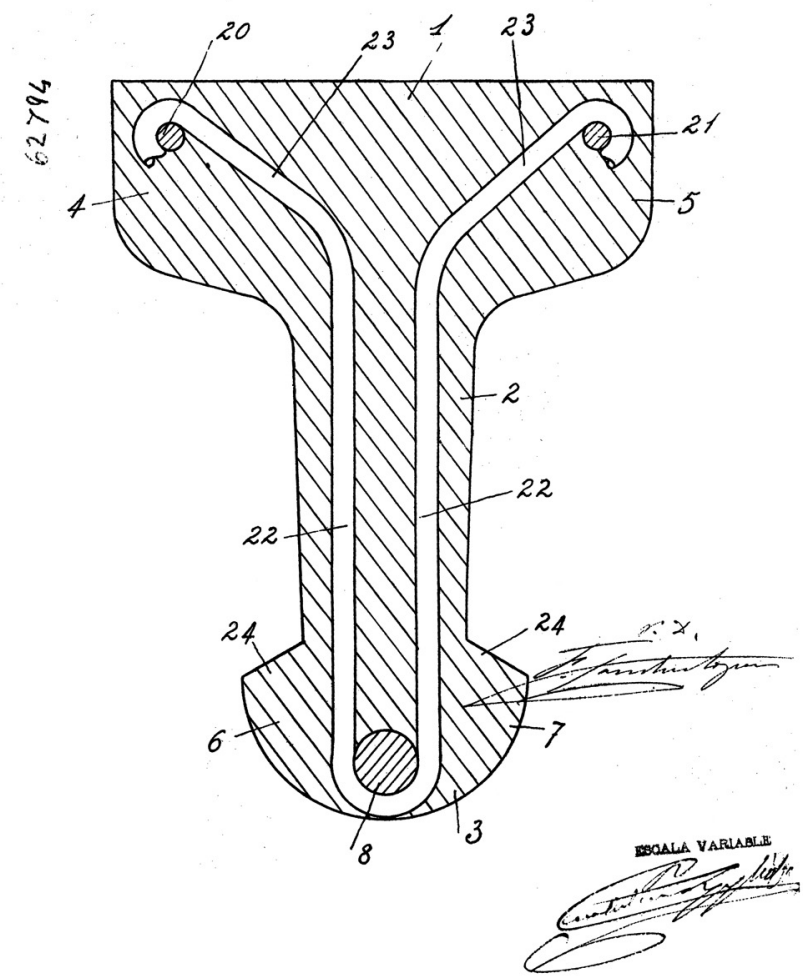

Figura 3. Hermanos Marial: vigueta prefabricada de hormigón armado «Semper-ita» [Fuente: AH-OEPM, Certificado de adición, 62.794 (1916)].

Las vigas Semper-ita se empezaron a fabricar en 1917 y tuvieron muy buena acogida, si se hace caso a la publicidad de la empresa que presumía de la colocación, básicamente en Barcelona (27), de 150.000 metros lineales de vigueta durante los dos primeros años (1917 y 1918) (Figuras 4 y 5). Su publicidad también afirmaba que la sustitución del acero por el hormigón armado permitía ahorros entre el 15 y el $20 \%$ del coste. En el mes de enero de 1919 se creó la empresa Marial Hermanos, Sociedad Colectiva (28), para fabricar y explotar el producto. Su fabricación se mantuvo una vez caducada la patente, alrededor de 1926, a través de varios fabricantes como Ribó y Jordán, S. Ltda.

La ambición empresarial de los Marial y sus relaciones sociales y políticas les permitieron presentar, en 1918, la vigueta Semper-ita en Madrid (29), con una amplia presencia de público especializado en la sesión práctica de construcción y pruebas de carga que se realizó el mes de diciembre. Efectivamente, al lado de la élite de la construcción madrileña estaba el ministro de Instrucción Pública y Bellas Artes Joaquim Salvatella, amigo del viejo constructor, el arquitecto Mauricio Jalvo, director de la revista El Cemento Armado, o el ingeniero de caminos Juan Manuel de Zafra, uno de los mejores conocedores de la nueva técnica. Los Marial instalaron una fábrica en Madrid y más tarde, ya muerto el padre, una empresa de construcción dirigida por Melcior Marial, el cual, siguiendo los pasos del fundador de la empresa, sería elegido diputado a Cortes por el Partido Republicano Federal.

La llegada de la Guerra Civil truncó todas estas aventuras y Melcior Marial, exiliado en Venezuela, volvió a patentar las viguetas allí y las comercializó mediante la empresa Compañía Anónima Semper-ita de Caracas (30). 


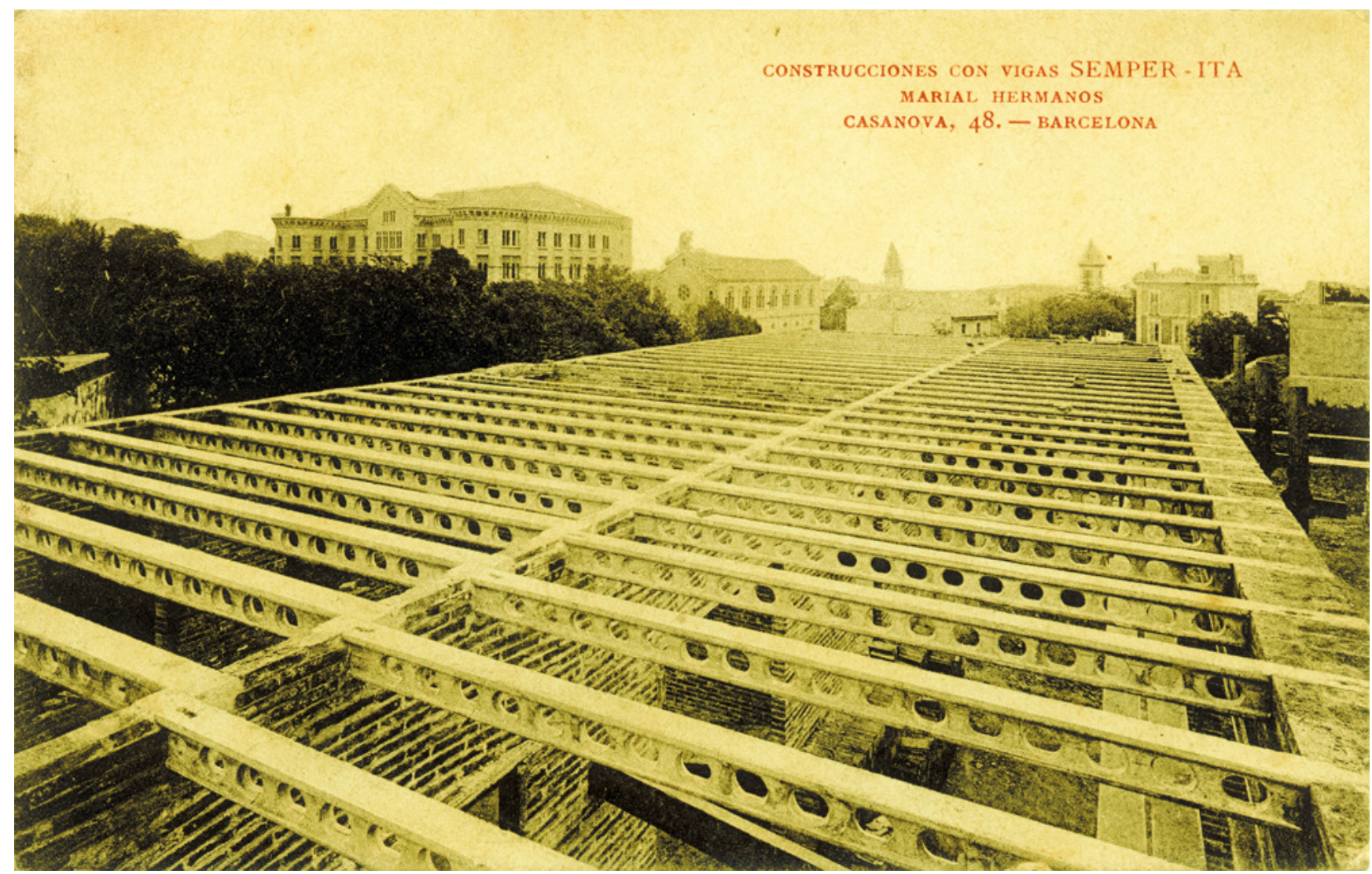

Figura 4. Hermanos Marial: construcción con vigas «Semper-ita» del Asilo Durán en la calle Vilana durante los años 20, Barcelona [Fuente: Colección R. Graus].

\section{EVIGAS SEMPER-ITA}

\section{de Cemento Armado Patentadas}

\begin{tabular}{|c|c|c|c|c|c|c|c|c|c|}
\hline \multirow{4}{*}{ Tipo } & \multicolumn{9}{|c|}{ Luces en metros que pueden salvarse con una carga uniformemente repartida por metro cuadrado de } \\
\hline & \multicolumn{3}{|c|}{$300 \mathrm{Kg}$. } & \multicolumn{3}{|c|}{$350 \mathrm{Kg}}$. & \multicolumn{3}{|c|}{$400 \mathrm{Kg}}$. \\
\hline & \multicolumn{3}{|c|}{ Distancia entre vigas } & \multicolumn{3}{|c|}{ Distancia entre vigas } & \multicolumn{3}{|c|}{ Distancía entre vigas } \\
\hline & 0,50 & $0 ; 75$ & $1^{\prime} 00$ & 050 & 075 & $1^{\prime} 00$ & 0450 & & $1^{\prime} 00$ \\
\hline$F$ & $4^{\prime} 12$ & $3 \times 30$ & $2^{\prime} 92$ & 380 & $3{ }^{\prime} 10$ & 270 & 357 & & 253 \\
\hline G & $5 ‘ 50$ & $4^{\prime} 45$ & 3.85 & 505 & $4^{\prime} 15$ & $3: 58$ & $4 ' 74$ & & $3 \cdot 35$ \\
\hline $\mathrm{H}$ & & $5 \cdot 30$ & 463 & 600 & $4^{\prime} 96$ & $4^{\prime} 29$ & 565 & $4^{\prime} 63$ & $4^{\prime} 00$ \\
\hline 1 & & 6880 & $5^{‘} 90$ & & 630 & $5^{\prime} 45$ & $7: 25$ & 590 & $5^{\prime} 10$ \\
\hline
\end{tabular}

Figura 5. Hermanos Marial: tabla de luces máximas de las vigas «Semper-ita», según el tipo de armado y la carga uniforme por $\mathrm{m}^{2}$ [Fuente: Vigas Semper-ita, 1916. Colección R. Graus].

\section{CONSTRUCCIONES Y PAVIMENTOS, S. A.}

A pesar de la extensión progresiva de la nueva técnica del hormigón armado en la Cataluña de principios de siglo XX, es evidente que la «construcción catalana» constituía un freno a la generalización de la nueva técnica (31). El hormigón armado podía imponerse, como se ha visto, en campos especializados como la construcción de depósitos, la prefabricación de elementos, o como una técnica genérica en el amplio campo de la obra pública, pero debido a la eficiencia técnica y económica de la «construcción catalana» su entrada en el sector de la vivienda era difícil. Para entender algunos aspectos de esta contradicción será útil realizar un paseo por la historia de una de las empresas catalanas más potentes de este primer tercio del siglo XX. Construcciones y Pavimentos, $S$. A., fue fundada en 1911 (32) como resultado de una transformación de la antigua empresa Miró Trepat y Cía. en Comandita ${ }^{5}$. Esta empresa familiar había sido fundada por el constructor,

5 Participada por los hermanos Miró i Trepat: Joan, Alexandre, Laureà, Maria Antònia y Josep Maria. 
descendiente también de constructores, Joan Miró i Trepat (1871-1944), a inicios de siglo XX, con la doble vocación de actuar cerca del poder económico y político en Barcelona y Madrid y sin descartar los contactos internacionales, y, a su vez, realizarlo desde una alta calificación técnica garantizada por dos jóvenes arquitectos, Lluís Homs Moncusí (18681956) y Eduard Ferrés i Puig (1872-1928), también emparentados con la familia Miró Trepat, que accedieron al staff de la empresa con el papel de director técnico, el primero, y de director artístico, el segundo (33).

Una de las primeras obras que construyó aquella nueva empresa fue la fábrica de cemento del Clot del Moro para la Compañía Asland (34), y esta relación vinculó Miró Trepat y Cía. a los círculos catalanes, madrileños y norteamericanos más o menos vinculados al «cohesive system», es decir, a aquella manera de construir de la empresa americana de Rafael Guastavino, basada en el ladrillo y la bóveda tabicada, que era contemplada como el camino natural de evolución de la «construcción catalana». En 1902, fruto de aquellas relaciones, Miró Trepat y Cía presentó un proyecto de Eduard Ferrés para levantar con "construcción rápida» ${ }^{6}$ un hotel para las Fiestas de Mayo de Madrid (35). Tres años después Miró Trepat y Cía., en colaboración con la firma británica Hughes, se adjudicó - aunque no la llegaría a ejecutar- la subasta para construir la Gran Vía de Madrid con «construcción catalana» (36).

Pero, en 1909, el empresario y el equipo técnico de Miró Trepat y Cía. en Comandita ya se habían dado cuenta de la necesidad de un cambio estratégico. En primer lugar, la empresa pasaría a llamarse Construcciones y Pavimentos, $S$. A., que de cierta manera recordaba los orígenes de Miró Trepat y Cía., cuando la explotación de una cantera de basalto en Amer le proporcionaba ventajas en las subastas de adoquinados de calles, pero miraba al mismo tiempo hacia los nuevos pavimentos, de calles y carreteras, ahora técnicamente distintos. Además se abandonaba el nombre del propietario al convertirse en sociedad anónima, modalidad mucho más adecuada para los movimientos de capital y para integrar en el consejo de administración nombres con gran influencia social, política y, especialmente, con una presencia destacada del sector cementero en los cargos ejecutivos. Y esto último era así, también porque se priorizó especializarse en la construcción con hormigón armado. Por estas razones la empresa se convirtió en concesionaria de Hennebique, la cual ya operaba en España, aunque raramente en Barcelona, contrató más técnicos (Joan Capmany i Capmany, jefe de la oficina técnica de Barcelona, y el ingeniero de caminos Rafael López Sandino, jefe de la oficina técnica de Madrid77) (37), colocó al director técnico, Lluís Homs, en el consejo de administración y mantuvo a Eduard Ferrés como director artístico, aunque la marca de la empresa pasaba siempre por delante de la autoría del arquitecto (38).

Después de algunas incursiones de poca envergadura y la intervención en varias obras públicas, los primeros edificios

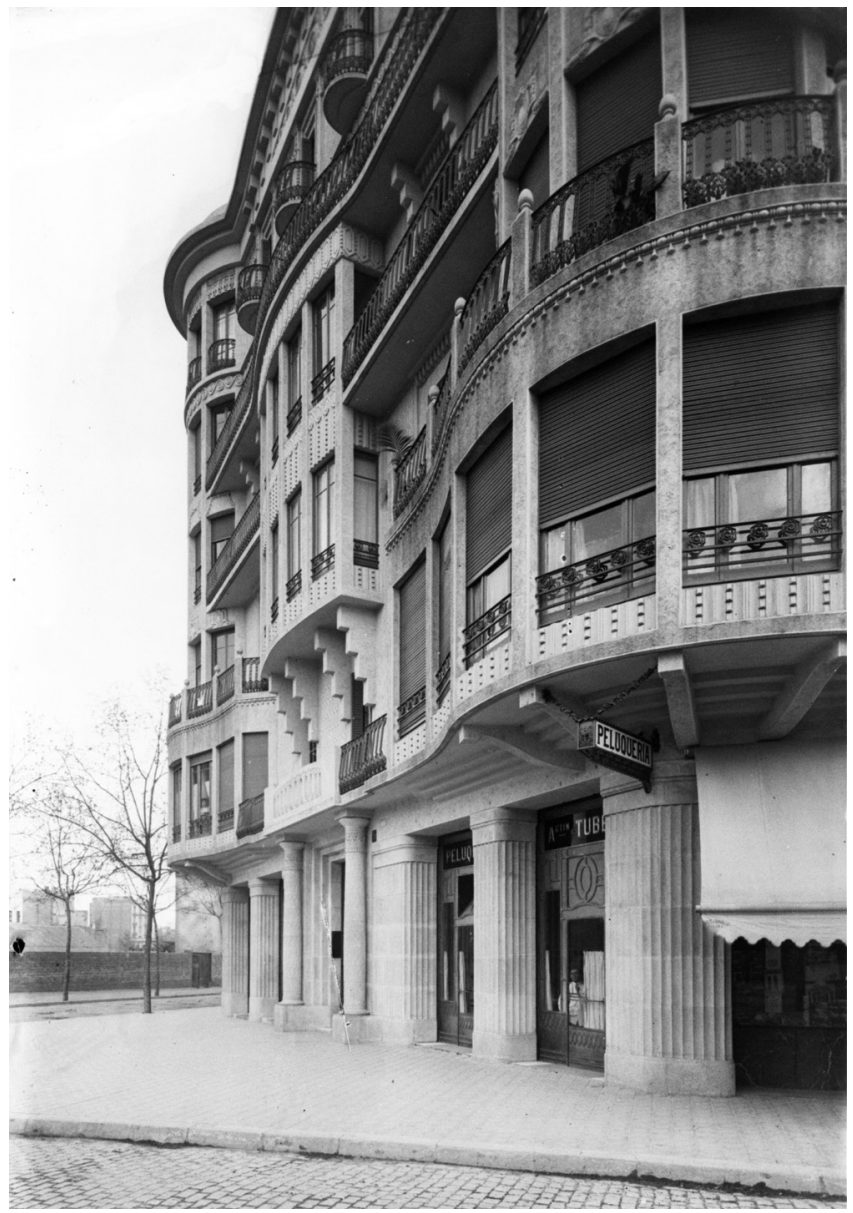

Figura 6. Construcciones y Pavimentos, S. A.: fachada de la casa Francesc Coll Portabella (1913), Barcelona [Fuente: Arxiu Nacional de Catalunya (ANC), Brangulí].

de hormigón armado que levantó en Barcelona fueron el de Carrocerías Farré (1911-1912) y el de los almacenes Sangrà (1911-1912), ambos en pleno Eixample, y hoy desaparecidos. Eran dos edificios con una composición similar, de aberturas generosas en planta baja y unos ventanales verticalizados en las plantas superiores. En el interior el sistema Hennebique se mostraba con su racional jerarquización estructural entre pilares, jácenas, viguetas y losas. No obstante, la gran dificultad que implicaba el hecho de introducir esta técnica en una localidad como Barcelona se hace muy evidente al analizar sus edificios de vivienda. Ignasi Coll i Portabella, que sería vicepresidente y después presidente del consejo de administración, encargó la construcción, entre 1912 y 1916, de cinco casas de alquiler para sus hermanos en la Gran Vía de Barcelona $^{8}$, entre las calles Borrell y Rocafort, proyectadas por Eduard Ferrés. Todos estos edificios fueron construidos y después publicitados como edificios de hormigón armado. En todo caso, un análisis detallado de estas casas permite ver como todas ellas fueron construidas con paredes de carga de ladrillo y solamente se utilizó la patente Hennebique en

\footnotetext{
${ }^{6}$ Una operación que podría recordar el mítico Hotel Internacional de 1888 en Barcelona, construido en 58 días entre varios contratistas entre los cuales estaba Joan Miró i Murtró, tío de Joan Miró i Trepat.

En 1919 la empresa tenía en plantilla a los ingenieros industriales Mateu, Boxó, López Sierra, Pueyo, Alonso, Poveda, Picabía, Manescau, Campalans y Boy, a los ingenieros militares Moreno-Zubia y Torrents y Biegbeder y a los arquitectos Fernández-Díaz, Rius, Marín y López Naya y los ingenieros extranjeros Lien, Bellvé, Pezzutti y Jamin.

8 Casa Ignasi Coll Portabella, Gran Vía, 461; Casa Joana Coll Portabella, Gran Vía, 481-485; Casa Pasqual Coll Portabella, Gran Vía, 493-495; Casa Francesc Coll Portabella, Gran Vía, 464-466, Barcelona.
} 


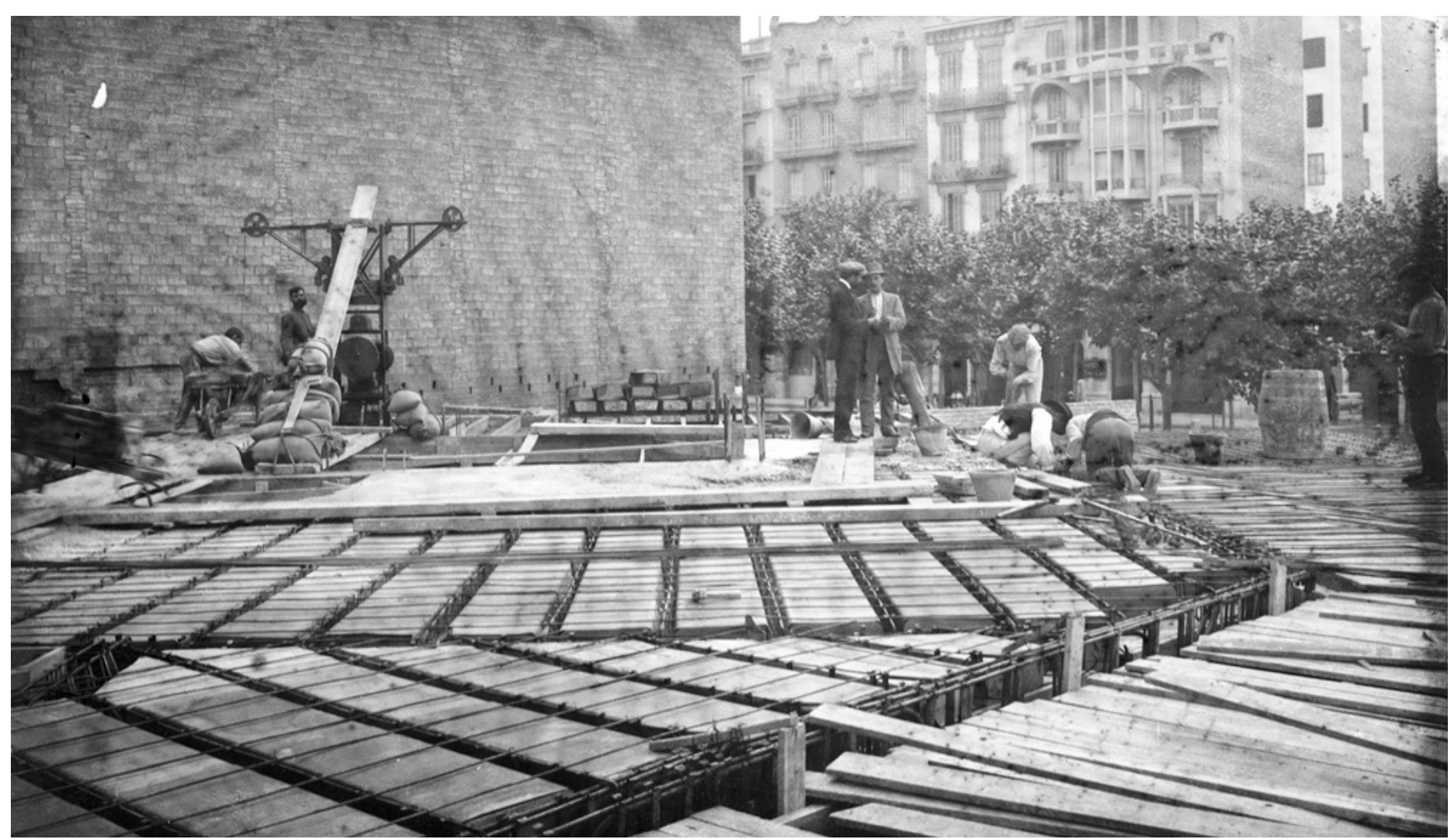

Figura 7. Construcciones y Pavimentos, S. A.: encofrado y armado de un forjado de la casa Francesc Coll Portabella (1913), Barcelona [Fuente: ANC, Brangulí].

los forjados unidireccionales encofrados in situ. Lo que permitía esta solución constructiva era sobre todo aumentar el juego formal de los elementos en voladizo de la fachada. La casa para Francesc Coll Portabella es un perfecto ejemplo de lo comentado. El forjado de cada planta salta hacia la calle con vuelos diferentes para formar tribunas o balcones, consiguiendo así una fachada inesperada en el Eixample (Figuras 6 y 7$)$.

Así, la nueva empresa acometía de manera prudente la introducción del hormigón armado dentro de la arquitectura residencial que ella tan bien conocía, y no debe extrañar que dentro de sus campañas de publicidad sobre las bondades del hormigón armado publicara también un anuncio de este tipo: «AVISO A LOS SEÑORES ARQUITECTOS, INGENIEROS Y PROPIETARIOS: La sociedad anónima 'Construcciones y Pavimentos', para evitar falsas interpretaciones, ha de significar que si bien realiza con gran éxito construcciones de hormigón armado, no ha excluido ni piensa abandonar ninguno de los sistemas constructivos conocidos y por lo tanto continúa ejecutando obras con viguetas, bovedillas, etc.» (39). En otras palabras, Construcciones y Pavimentos, S. A., comprendía las dificultades que implicaba luchar contra la tradición y no deseaba perder clientes, aunque ya hubiera virado hacia la nueva técnica.

En definitiva, hasta la Guerra Civil, la empresa construirá una cantidad respetable de edificios de hormigón armado, entre ellos son especialmente conocidos la Unión de Fotograbadores (1912-1913) (Figura 8), los almacenes Damians (después El Siglo) en la calle Pelai (1913), la Central Térmica del Besòs para Energía Eléctrica de Cataluña (1912-1913), la sede de la
Caixa de Pensions en Via Laietana (1914-1917), el Hotel Ritz (1917-1919), el Palacio de la Industria (hoy Palacio de Victoria Eugenia) de la Exposición (1922-1923) (Figura 9), el Autódromo de Terramar-Sitges (1922-1923) o el Estadio de Montjuïc (1928-1929) (Figura 10). Como ya había hecho Hennebique, la empresa emprendió un proyecto modernizador que incluía una activa publicidad basada en el registro fotográfico de sus obras. Por ejemplo, en el número especial de 1919 que editó la Revista de Arquitectura (40) se publicaron seis artículos profusamente ilustrados con fotografías de Josep Brangulí i Soler, que fue contratado por la empresa para realizar el seguimiento de las obras y dejar testimonio de la brillantez de los resultados. Sin embargo, la empresa no resistió la crisis de los años 30 y la Guerra Civil. Así, ya en 1943 se acordaba disolver y liquidar la sociedad (41) y en 1944 moría Joan Miró i Trepat.

\section{MATERIAL Y OBRAS, S. A.}

Lejos de los gentilicios, Material y Obras, $S$. A., era un nombre moderno, que podía sugerir cantidad de material y cualquier tipo de obras, acaso no sólo monumentos ni viviendas, sino obras grandes y abundantes... obras públicas, especialmente de comunicaciones y transportes.

Éste era el ADN de la empresa que con el nombre Material y Obras, S. A. (42), nacía en 1916 en Barcelona con un capital social de 500.000 pesetas, a partir del acuerdo de fusión de una familia de constructores, los Masana ${ }^{9}$, y un arquitecto, las características del cual fueron decisivas para aquella aventura: Salvador Soteras i Taberner (1864-1925). Soteras que un día sería calificado por Alexandre Soler i March de

9 El hombre fuerte de la familia era Joaquim Masana Bru (1881-1961) que compartía con Salvador Soteras el cargo de director-gerente, con pleno control de la empresa. 


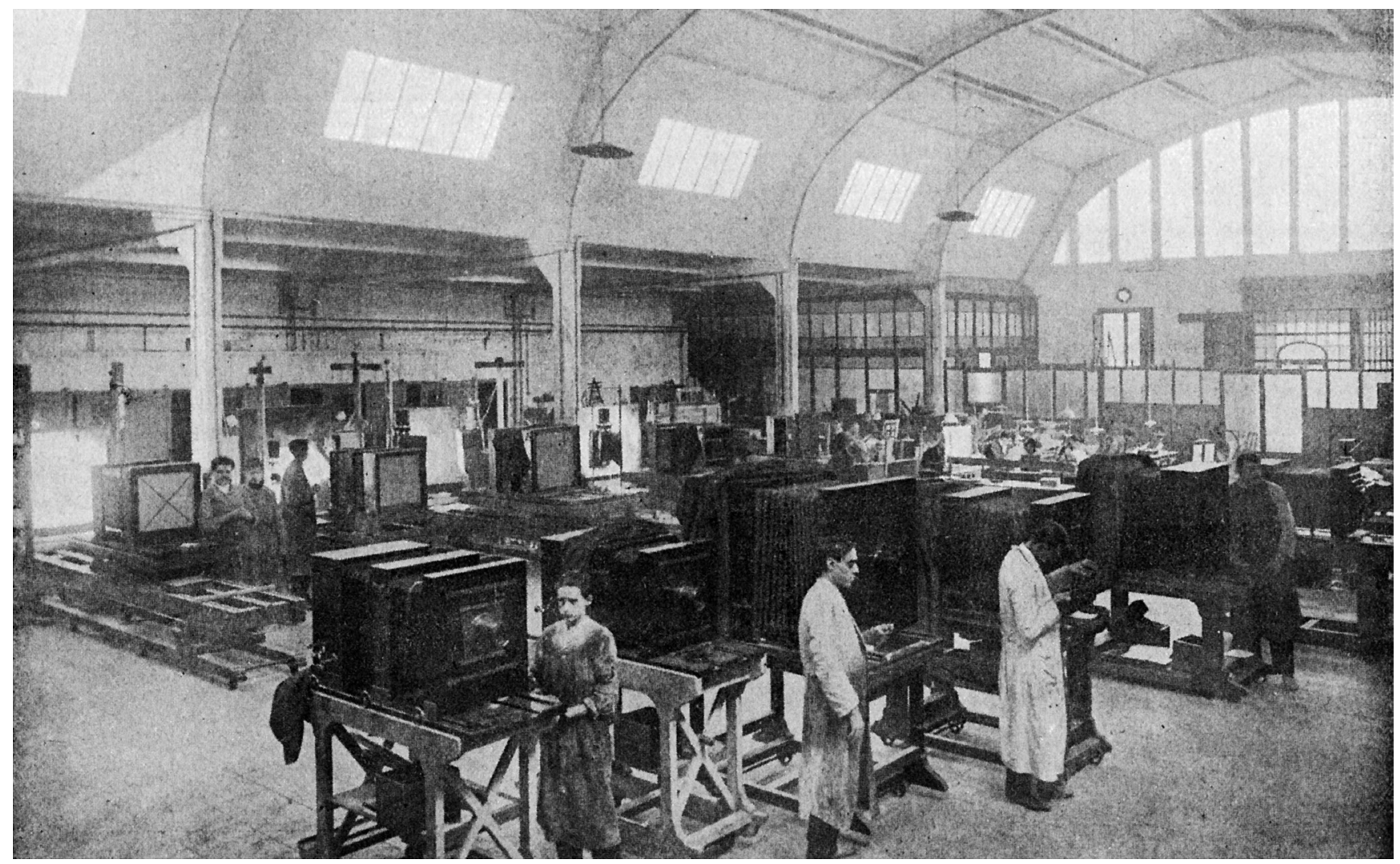

Figura 8. Construcciones y Pavimentos, S. A. Unión de Fotograbadores (1912-1913), diseñado por E. Ferrés, Barcelona [Fuente: Barcelona artística e industrial, 1917].

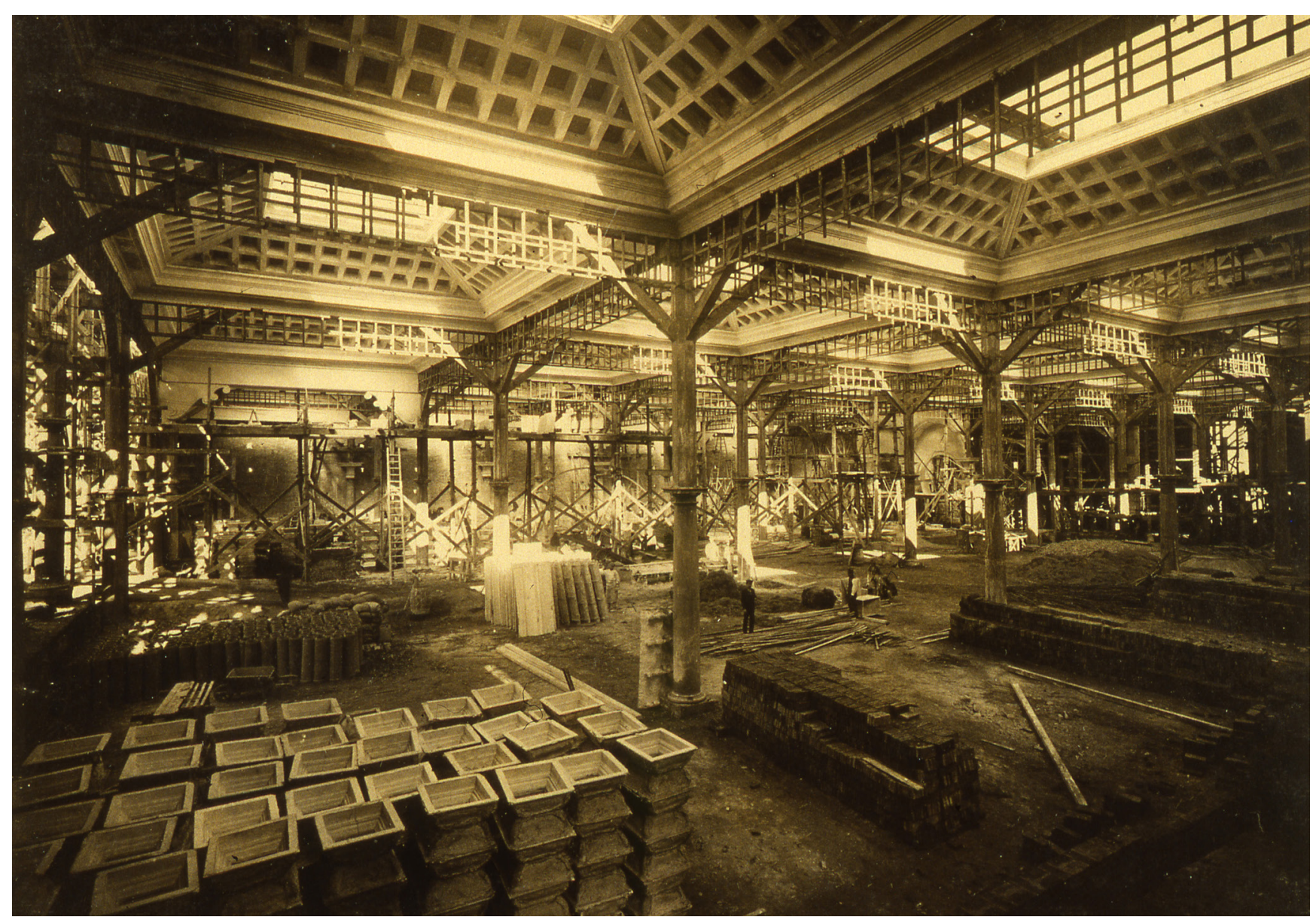

Figura 9. Construcciones y Pavimentos, S. A.: estructura de hormigón armado del Palacio de la Industria (hoy Palacio de Victoria Eugenia) de la Exposición (1922-1923), diseñado por J. Puig i Cadafalch, Barcelona [Fuente: Arxiu Fotogràfic de Barcelona (AFB)]. 


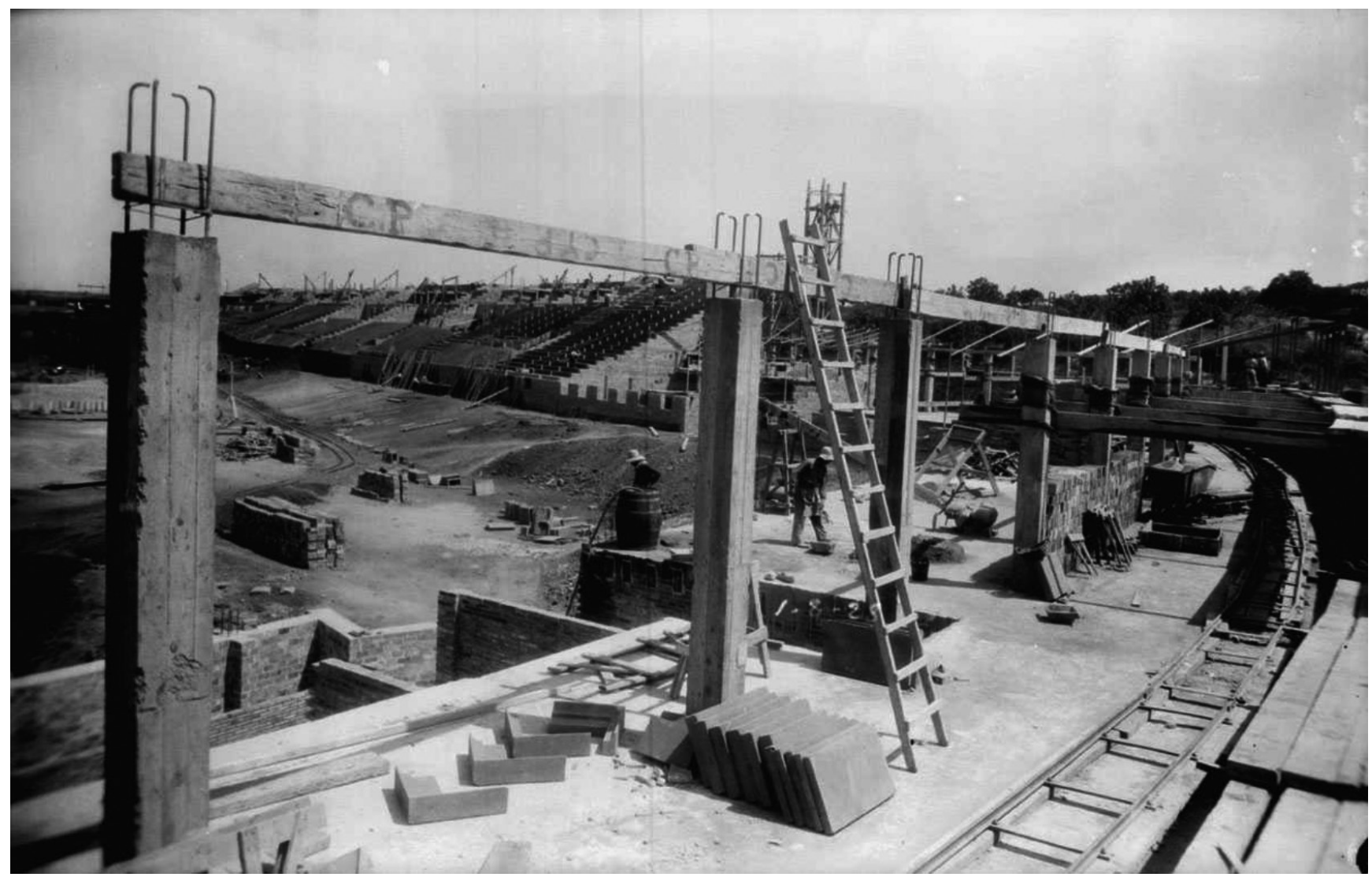

Figura 10. Construcciones y Pavimentos, S. A.: obras de hormigón armado en el Estadio de Montjuïc (1928-1929), diseñado por P. Domènech i Roura, Barcelona [Fuente: ANC, Brangulí].

«hombre práctico y progresivo... con el temple de un técnico americano» (43), era un arquitecto bregado y experto en la construcción del ferrocarril; no únicamente porque trabajara para la compañía ferroviaria $M$. Z. A., donde había proyectado, por ejemplo, las obras del Apeadero del Passeig de Gràcia (1902) o de la Estación de Badalona (1910); sino porque había trabajado él mismo de constructor, ganando importantes subastas como la de construir 2 puentes y 12 túneles para la línea Ripoll-Puigcerdà (1912).

El mismo Soler i March recordaba que la empresa Material y Obras, $S$. A., «prontamente después de crearse se expandió notablemente, significándose de una manera especial en las obras derivadas de la unión del hierro con el cemento». Se trataba, pues, de una empresa creada expresamente para la obra pública con hormigón armado. Técnica que la empresa utilizó con profusión desde sus inicios en la construcción del nuevo Cementerio del Sudoeste y a partir de 1923 en la cobertura del gran colector del Bogatell, ambos en Barcelona.

A partir de 1920 Material y Obras, S. A., aprovechando la experiencia de Soteras en M. Z. A., consiguió una parte de la contrata para la construcción de la Estación de Francia de Barcelona. La gran terminal, proyectada por el arquitecto Pedro Muguruza, estaba conformada por un edificio en forma de U que envolvía los andenes, y estaba siendo construida aparentemente de manera tradicional. Entre 1920 y 1924 se construyó con obra de fábrica el interior de uno de los brazos de la U, el más oriental, con pilares y jácenas metálicas y con forjados con losas de hormigón armado y, entre 1925 y 1927 , el interior del brazo occidental, ya todo él de hormigón armado y levantado por Material y Obras.
Después, cuando se vislumbraba la celebración de la Exposición Internacional de 1929, Material y Obras, S. A., usó masivamente el hormigón armado en varias obras previas. Primero, a partir de 1926, en la Estación del tren de Sarrià, bajo las calles Pelai y Bergara, con bóvedas y columnas clásicas, incluido el tramo del túnel de la calle Balmes hasta la Diagonal y, a partir de 1927, en el vestíbulo, escalinatas y fuentes de la parte de montaña de la plaza de Catalunya. Más tarde, ya en 1929, ejecutó una nueva contrata para las estaciones del Metro Transversal también bajo la plaza, aquí la estructura se presentaba con jácenas acarteladas y pilares fungiformes de gran expresividad (Figura 11).

Salvador Soteras murió en 1925, pero los Masana continuaron la empresa y se adjudicaron uno de los grandes complejos de la Exposición de 1929: el Pueblo Español de Montjuïc, una obra de gestación compleja (44) que exigía unos tiempos de realización muy reducidos, ya que se adjudicó en enero de 1928 cuando faltaba muy poco tiempo para su apertura. Se trataba de reproducir la arquitectura de las distintas regiones españolas con un revestimiento de piedra artificial sobre una estructura de madera. Sin embargo, Material y Obras $S$. $A$., ganó la contrata proponiendo la sustitución de aquella estructura de madera por una estructura de hormigón armado. La nueva estrategia permitía superponer la fragmentación decorativa de cada una de las casas del pueblo sobre una trama estructural homogénea de hormigón armado a gran escala (Figura 12).

El hormigón armado empezaba a propiciar empresas especializadas, es decir, que ante todo construían obras con el nuevo material a precios competitivos. 


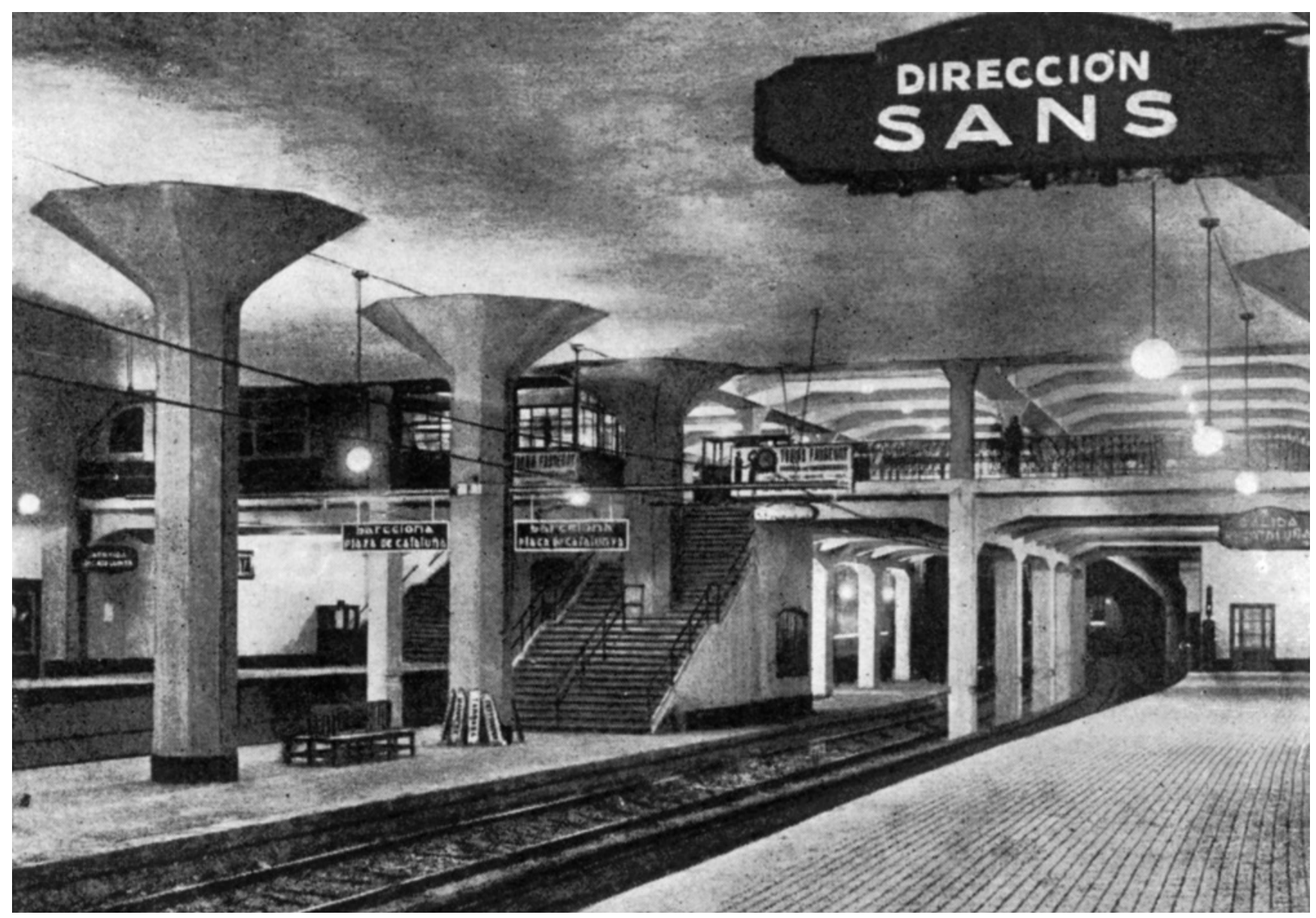

Figura 11. Material y Obras, S. A.: estación subterránea de plaza de Catalunya (1929-1930) de los Ferrocarriles del Norte y del Metro Transversal, Barcelona [Fuente: Manual del cemento Portland, 1933].

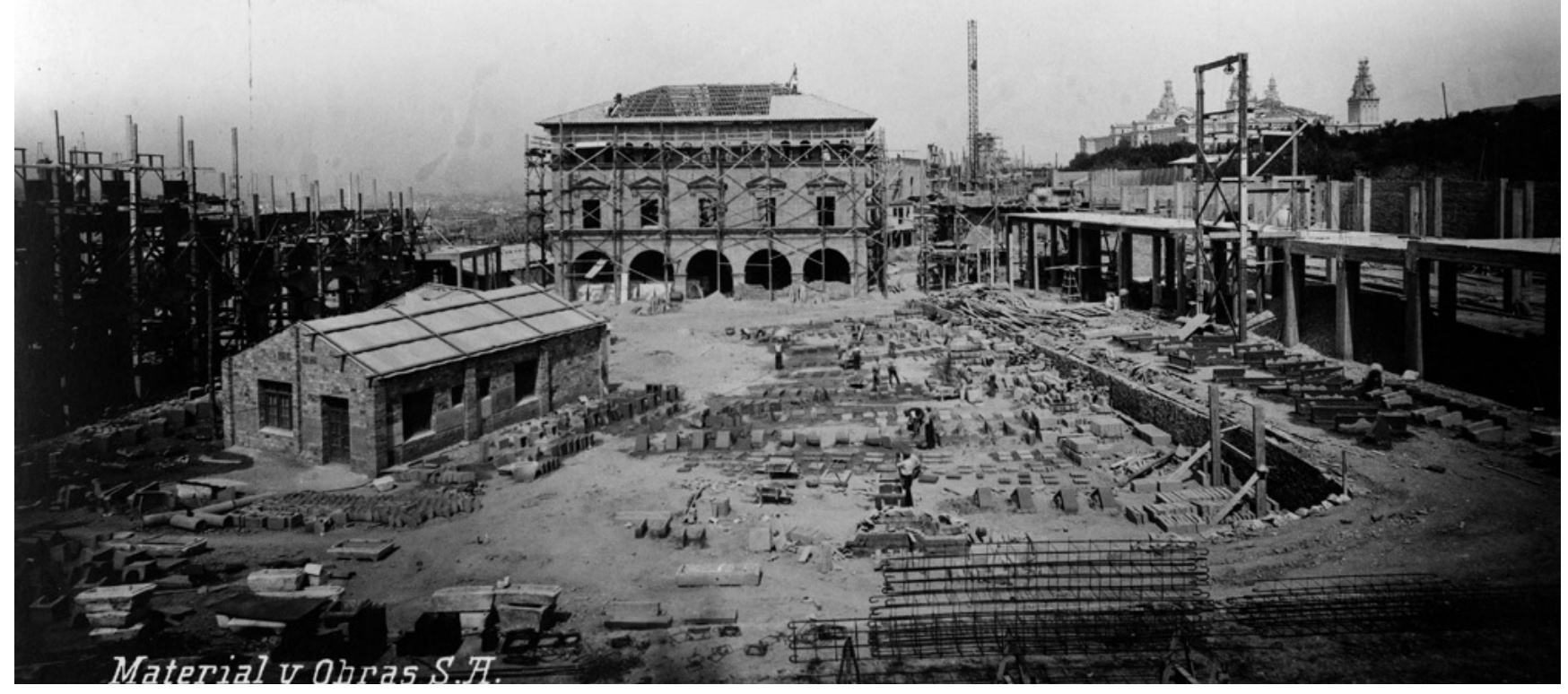

Figura 12. Material y Obras, S. A.: estructura de hormigón armado antes de ser revestida con piedra artificial para conformar las casas tradicionales del Pueblo Español, Barcelona (1928) [Fuente: AFB]. 


\section{LÍMITES DE LA INVESTIGACIÓN}

Los archivos de las cuatro empresas que hemos presentado desaparecieron al quebrar cada una de las empresas. La documentación que hemos manejado pertenece al dominio público (Registro Mercantil, Oficina de Patentes, Archivo de Protocolos Notariales, archivos municipales, etc.) o ha llegado a nuestros días en forma de publicidad. Lamentablemente, no hemos podido localizar aquella información técnica (planos detallados de ejecución, normativa aplicada, calidad y origen de los materiales utilizados, etc.) que permita profundizar en cómo se asimilaban las novedades que aparecían en libros y normativas extranjeras. Solamente el análisis detallado de cada una de las obras quizás podría aportar datos nuevos. Por otro lado, ninguna de las cuatro empresas tuvo técnicos que simultanearan la obra y la docencia universitaria (como un Ribera o un Zafra), hecho que limita su legado teórico. Sin embargo, podemos afirmar que su aportación principal fue el desarrollo de una escala nueva de empresa constructora, ahora especializada en hormigón armado, de gran capacidad organizativa (de manera especial las empresas Construcciones y Pavimentos, S. A., y Material y Obras, S. A.) que permitió modernizar el sector constructivo catalán, anclado profundamente en la tradición del ladrillo. Sin embargo, el ciclo económico depresivo 1929-1952 lastró estas iniciativas y alargó artificialmente los restos de la tradicional «construcción catalana».

\section{REFERENCIAS}

(1) Peña Bœuf, A. (1953). Un siglo de hormigón armado en España. Revista de Obras Públicas, 101(2857): 23-32.

(2) Páez, A. (1956). Cincuenta años de hormigón armado en España. Revista de Obras Públicas, 104(2892): $201-209$.

(3) Bassegoda Nonell, J. (1987). El hormigón armado. En Morales, J. L. (Ed.), Historia de la arquitectura española, tomo 5 (pp. 1802-1807). Zaragoza: Exclusivas de Ediciones, Planeta.

(4) Tarragó, S. (Ed.) (1982). J. Eugenio Ribera: Ingeniero de Caminos, 1864-1936, Madrid: Colegio de Ingenieros de Caminos, Canales y Puertos.

(5) Martín Nieva, H. (2000). Claudi Duran i el formigó armat a Catalunya (Trabajo final de los estudios de Arquitectura Técnica no publicado). Barcelona: Universitat Politècnica de Catalunya (UPC).

(6) Rosell, J. (1996). Los orígenes del hormigón armado. En Rosell, J., Cárcamo, J. (Eds.), Los orígenes del hormigón armado y su introducción en Bizkaia: La fábrica Ceres de Bilbao (pp. 13-48). Bilbao: Bizkaiko Aparailari eta Arkitekto Teknikoen Elkargo Ofiziala.

(7) Rosell, J. (2000). Los inicios del hormigón armado: de las patentes a la normativa de uso. En Casanovas, X. (Ed.), Manual de diagnosis e intervención en estructuras de hormigón armado (pp. 13-18). Barcelona: Col·legi d’Aparelladors i Arquitectes Tècnics de Barcelona.

(8) Martín Nieva, H. (2000, 26-28 de octubre). La introducción del hormigón armado en España: las primeras patentes registradas en este país. En Graciani, A., Huerta, S., Rabasa, E., Tabales, M. Á. (Eds.), Actas del Tercer Congreso Nacional de Historia de la construcción, volumen II (pp. 673-681). Sevilla: Instituto Juan de Herrera, SEHC, Universidad de Sevilla, Junta de Andalucía, COAATG, CEHOPU.

(9) Cárcamo, J. (1996). La introducción del hormigón armado en Bilbao: La fábrica Ceres. En Rosell, J., Cárcamo, J. (Eds.), Los orígenes del hormigón armado y su introducción en Bizkaia: La fábrica Ceres de Bilbao (pp. 51-116). Bilbao: Bizkaiko Aparailari eta Arkitekto Teknikoen Elkargo Ofiziala.

(10) Burgos Núñez, A. (2009). Los orígenes del hormigón armado en España. Madrid: Ministerio de Fomento, CEDEXCEHOPU.

(11) Graus, R. (2012). Modernització tècnica i arquitectura a Catalunya, 1903-1929 (Tesis doctoral no publicada). Barcelona: Universitat Politècnica de Catalunya, http://hdl.handle.net/10803/98250.

(12) Nicolau i Bujoms, J. (1909, 22 de marzo). Protocolo n. ${ }^{\circ}$ 248. Arxiu Històric de Protocols de Barcelona (AHPB).

(13) Graus, R., y Rosell, J. (2011). El paper de Joan Torras Guardiola en l'arquitectura del seu temps. En Feliu i Torras, A., Vilanova, A. (Eds.), La Barcelona de ferro: a propòsit de Joan Torras Guardiola (pp. 35-90). Barcelona: Museu d'Història de Barcelona.

(14) Ribera, J. E. (1902). Hormigón y cemento armado: Mi sistema y mis obras, pp. 24-27, Madrid: Imprenta de Ricardo Rojas.

(15) Nicolau i Bujoms, J. (1908, 27 de agosto). Protocolo n. ${ }^{0}$ 716. Arxiu Històric de Protocols de Barcelona (AHPB).

(16) Nicolau i Bujoms, J. (1908, 23 de septiembre). Protocolo n. ${ }^{0} 770$. Arxiu Històric de Protocols de Barcelona (AHPB).

(17) Nicolau i Bujoms, J. (1909, 22 de marzo). Protocolo n. ${ }^{\circ}$ 248. Arxiu Històric de Protocols de Barcelona (AHPB).

(18) Campllonch, I. (1917). Cellers cooperatius de producció i venda: cooperació agrícola, p. 108, Barcelona: Diputació Provincial de Barcelona.

(19) (1914, 3 de octubre). Claudio Duran y Ventosa... La Vanguardia, p. 2.

(20) (1918, 30 de abril). Anónima Claudio Durán: Construcciones Monier. La Vanguardia, p. 14.

(21) Catà i Catà, E. (1926). D. Claudi Durán. Anuario de la Asociación de Arquitectos de Cataluña: 139-141.

(22) Burgos Núñez, A. (2012). Les premiers planchers de béton armé en Espagne. En Gargiani, R. (Ed.), L’architrave, le plancher, la plate-forme: Nouvelle histoire de la construction (pp. 559-565). Lausanne: Presses Polytechniques et Universitaires Romandes.

(23) Marial, J., Marial, M. (1916, 3 de marzo). Perfeccionamientos en las vigas de cemento armado. Patente de invención (61.876). Archivo Histórico, Oficina Española de Patentes y Marcas (AH-OEPM).

(24) Marial, J., Marial, M. (1916, 9 de agosto). Perfeccionamientos en las vigas de cemento armado. Certificado de adición (62.794). Archivo Histórico, Oficina Española de Patentes y Marcas (AH-OEPM). 
(25) Marial, J., Marial, M. (1916, 11 de noviembre). Perfeccionamientos en las vigas de cemento armado. Patente de invención (63.325). Archivo Histórico, Oficina Española de Patentes y Marcas (AH-OEPM).

(26) (1916, 1 de agosto). Marca 28.914. Boletín Oficial de la Propiedad Industrial, n. ${ }^{\circ}$ 719: 1043.

(27) (1919). El mejor elogio... Arquitectura y Construcción: 319.

(28) (1919, 22 de enero). Hoja 12.242, Inscripción 1. Registro Mercantil de Barcelona (RMB).

(29) (1919). Sustitución del hierro por el cemento en las construcciones modernas. Mundo gráfico, IX(376): 19.

(30) (1942, 23 de mayo). Gaceta Oficial de los Estados Unidos de Venezuela (20.804): 137197.

(31) Graus, R., y Rosell, J. (2009). El Ensanche Cerdà y la «construcción catalana». En Guàrdia, M. (Ed.), El Ensanche: génesis y construcción (pp. 97-103). Barcelona: Lunwerg.

(32) (1911, 1 de junio). Hoja 1.404, Inscripción 1, f. 29v-38r. Registro Mercantil de Girona (RMG).

(33) Ferrés, X., Folch, A., Folch, R. (1997). Eduard Ferrés i Puig, arquitecte. Vilassar de Mar: La Comarcal, Ajuntament de Vilassar de Mar, Amics de Vilassar de Mar.

(34) Douet, J. (2007). The Turnkey Factory: Technology Transfer from America to Spain in the Portland Cement Industry. IA: The Journal of the Society for Industrial Archeology, XXXIII(1): 27-37.

(35) Cuenca, C. L. de (1902). Proyecto de Gran Hotel para las fiestas de Mayo. La Ilustración Española y Americana, XLVI(6): 90, 100.

(36) (1905, de 24 de septiembre). La Gran Vía. El Liberal: [2]

(37) (1919). El hormigón armado en España. Revista de Arquitectura: 183, 197.

(38) Conill, B. (1928). N’Eduard Ferrés i Puig. En Anuario de la Asociación de Arquitectos de Cataluña: 87-91.

(39) (1913, 14 de septiembre). Aviso a los señores arquitectos, ingenieros y propietarios. La Vanguardia: 4.

(40) (1919). El cemento armado en España. Revista de Arquitectura: 149-260.

(41) (1949, 25 de febrero). Hoja 1.404, Inscripción 1, f. 96r-97v. Registro Mercantil de Girona (RMG).

(42) (1916, 7 de julio). Hoja 10.169, Inscripción 1. Registro Mercantil de Girona (RMG).

(43) Soler i March, A. (1925). [Nota necrológica] D. Salvador Soteras y Taberner. Anuario de la Asociación de Arquitectos de Cataluña: 105-108.

(44) Bengoechea, S. (2004). Els secrets del Poble Espanyol, 1929-2004. Barcelona: Poble Espanyol de Montjuïc, S A. 